\title{
ASSOCIATION BETWEEN MATERNAL ANEMIA WITH STUNTING INCIDENCE AMONG NEWBORNS IN SURAKARTA, CENTRAL JAVA
}

\author{
Safitri Tia Tampy, Hari Wahyu Nugroho, Rahmi Syuadzah \\ Pediatric Research Center (PRC), Department of Pedicatric Science, \\ Dr Moewardi General Hospital, Surakarta, Central Java
}

\begin{abstract}
Background: Stunting is one of the global nutrition problems, which is recorded in the six global nutrition targets in 2025. Stunting is defined as a condition when a child's body length or height based on age and sex is below -2 SD of the median standard of child growth by World Health Organization. The prevalence of stunting in newborns in the world is $3.8 \%$. The causes of stunting are multifactorally occurring from the age of conception to the age of two. Factors that influence stunting of newborns during the prenatal period are maternal height, maternal weight gain, anemia, and infection during pregnancy. Anemia occurs in 37\% of pregnant women. Maternal anemia causes disruption in fetal growth which increases the risk of stunting at birth. This study aimed to examine the Association between maternal anemia with stunting incidence among newborns in Surakarta, Central Java.

Subjects and Method: This was a cross-sectional study conducted at Sibela Community Health Center, Surakarta, Central Java. Total of 184 third trimester pregnant women and 184 newborns were enrolled in this study. The dependent variable was stunting among newborns. The independent variable was anemia in pregnant women. The data were taken from medical records in the period February-March 2020. The data were analyzed using Chi-square.

Results: The prevalence of stunting among newborns was 8.2\%. Anemia among pregnant women were $31.0 \%$. Pregnant women who had anemia increase the incidence of stunting among newborns (OR $=5,19 ; 95 \% \mathrm{CI}=1.69$ to $15.99 ; \mathrm{p}=0.002)$.

Conclusion: There is a relationship between anemia among pregnant women and the incidence of stunting among newborns.
\end{abstract}

Keywords: anemia, pregnancy, stunting, newborn

\section{Correspondence:}

Safitri Tia Tampy. Pediatric Research Center (PRC), Department of Pediatric Science, Dr Moewardi General Hospital, Surakarta, Central Java

The $7^{\text {th }}$ International Conference on Public Health

Solo, Indonesia, November 18-19, 2020 | 191 https://doi.org/10.26911/the7thicph.03.11 